\title{
GAME DESIGN E HCI: A IMPORTÂNCIA DE ESTUDOS E PESQUISA NO PROCESSO DE DESENVOLVIMENTO DE JOGOS DIGITAIS
}

\author{
Priscilla Bensabath Azoubel \\ Universidade Federal do Maranhão \\ pitibensabath@gmail.com \\ Lorena Viana Pina \\ Universidade Federal do Maranhão \\ lorenavpina@gmail.com \\ André Leonardo Demaison \\ Universidade Federal do Maranhão \\ demaison@gmail.com \\ Lívia Flávia de Albuquerque Campos \\ Universidade Federal do Maranhão \\ liviaflavia@gmail.com
}

Resumo: Este artigo apresenta uma revisão atualizada sobre a importância da pesquisa e dos processos metodológicos no desenvolvimento de jogos digitais. Objetiva-se analisar importantes elementos, características e processos dos métodos conhecidos de desenvolvimento de jogos digitais, processos esses que passaram por diferentes mudanças e adaptações ao longo dos anos, principalmente a partir do momento em que teve início a demanda por jogos que podem ser utilizados também no ensino de conteúdos e na reabilitação de pacientes. Tais modalidades exigem um maior cuidado no projeto tanto para atender às necessidades demandadas pelas condições do usuário como para facilitar a obtenção de feedbacks e resultados para o profissional responsável por ele. É necessário ainda proporcionar uma experiência mais completa e interativa com o jogo, possibilitando a resolução de desafios ao usuário e sua consequente satisfação com o software. Apesar da reabilitação em si não ser o foco neste trabalho, o mesmo faz parte de uma pesquisa maior que está sendo desenvolvida pelos autores sobre o uso de jogos digitais em processos de reabilitação.

Palavras-chave: Jogos, usabilidade, interface

Abstract: This article presents an updated review of the importance of research and methodological processes in the development of digital games. The objective is to analyze important elements, features and processes of the known methods of developing digital games, which processes have undergone different changes and adaptations over the years, especially from the moment that began the demand for games that can be used to 
teach and/or to rehab patients. Such arrangements require greater care in the project both to meet the needs required by the user conditions and to facilitate obtaining feedback and results to the professional responsible for it. It is necessary to provide more complete and interactive experience with the game, allowing the resolution of game's challgenges and its consequent satisfaction with the software. Even though the rehabilitation itself is not the focus of this paper, it is part of a larger research being developed by the authors on the use of digital games in rehabilitation processes.

Keywords: Games, usability, interface

\section{INTRODUÇÃO}

O processo de desenvolvimento de um jogo dá-se de forma extensa, complexa e demanda a presença de profissionais de diferentes áreas para alcançar um resultado final satisfatório. Diferentes testes são necessários para evitar que erros e falhas passem despercebidos, atrapalhando a produção final do jogo (Breyer et al, s.d). Os métodos e técnicas utilizados são constantemente atualizados e, juntamente com o levantamento teórico e a pesquisa técnica/científica, tornam-se os pilares para um bom design de jogo digital, sendo esse o objetivo de um novo desenvolvimento.

Os jogos divertem e entretêm seus usuários ao deixá-los imersos em seu universo, fazendo com que aproveitem toda a sua capacidade. Para atingir tal objetivo, alguns pontos são levados em consideração durante o desenvolvimento: roteiro, usabilidade, interface, efeitos e desafios. Um jogo enfadonho e de difícil compreensão corre o risco de ser facilmente descartado pelo usuário. A execução dos testes de usabilidade, interface e jogabilidade são importantes para evitar que tal fato ocorra. (Medeiros, 2015).

Atualmente existe uma grande demanda por jogos que possam ser utilizados para o ensino de pessoas e reabilitação de pacientes (Medeiros Filho et al, 2013). São jogos que precisam entreter o usuário ao mesmo tempo em que trabalham questões demandadas pelas necessidades do mesmo, mantendo-o motivado a continuar com seu aprendizado ou tratamento.

Para garantir a efetividade de um jogo é necessária a realização de diferentes avaliações e técnicas. A prototipagem pode ser citada como um exemplo eficiente e pode ocorrer em diferentes etapas do projeto (Medeiros Filho et al, 2013). Outra ferramenta importante é a avaliação heurística, que auxiliará no encontro de erros, falhas de interface e jogabilidade antes do produto final ficar pronto. Considerando que os jogos possuem essas diversas finalidades (diversão, educação, reabilitação e outras), torna-se de suma importância a correta condução das etapas metodológicas e das pesquisas a fim de atingir o objetivo proposto.

\section{JOGOS DIGITAIS}

Schuytema (2008, apud Lucchese e Ribeiro, 2009) explica que jogo eletrônico é uma "atividade lúdica formada por ações e decisões que resultam numa condição final. Tais ações e decisões são limitadas por um conjunto de regras e por um universo, que no contexto dos jogos digitais, são regidos por um programa de computador". É o 
universo em que o jogo está inserido que determina o tema, as ações que os jogadores terão que realizar, objetivos, limitações, desafios e regras específicas para a continuidade da atividade. Projetados para serem usufruídos em mídias digitais, telefones, computadores e consoles, além de jogos exclusivamente utilizados no virtual, alguns desses jogos são versões virtuais de jogos que existem no meio físico, como os de baralho e tabuleiro, refletindo o 'mundo real' dentro do virtual (Lucchese e Ribeiro, 2009).

Jogos digitais são elementos constantes no cotidiano de grande parte da população atualmente. Seja para um simples passatempo ou em nível profissional é inquestionável a importância dos games e a variedade de temas dos mesmos. Sato (2010), ao começar a conceituá-los, traz a reflexão do filósofo Johan Huizinga, explicando que os jogos fazem parte da sociedade e da sua cultura, possuindo valores e anseios que agradam e identificam-se com elas, servindo como formas de expressão.

A procura pelos jogos digitais acontece de forma espontânea, visando uma forma diferente de diversão (Alves e Padovani, 2006). Porém, atualmente são desenvolvidos jogos cujo principal objetivo não é o entretenimento, mas o uso para fins terapêuticos e educacionais (Peres et al, 2012). A diversão, entretanto, não pode ser excluída. Colocada de maneira correta e estratégica, conquista os usuários, estimulando-os a continuar com o jogo (Cybis, 2010). Nesse ponto, fica clara a importância das pesquisas e técnicas utilizadas, a fim de que o objetivo desejado com o desenvolvimento seja alcançado - se o entretenimento puro e simples ou se fins como educação ou reabilitação. O design participativo, no qual o usuário torna-se peça fundamental para o desenvolvimento do produto, pode ser o grande diferencial nas etapas de definição dos objetivos do jogo.

Independente da finalidade, o jogo é um software e, como tal, precisa passar por diferentes etapas e testes até chegar ao produto final (Junior et al, 2002). Peres et al (2012, apud Clua, 2008) afirma que existem diferentes técnicas para o desenvolvimento dos jogos que visam integrar ainda mais os sentidos da visão e da audição, além dos sensores de movimentos, permitindo que a experiência do jogo possa ser sentida por todo o corpo.

A projetação de um jogo dá-se de forma multidisciplinar e multifuncional, envolvendo as equipes responsáveis pelo Game Design, Programação, Artes, e outras áreas necessárias. Esse trabalho conjunto permite que o processo de desenvolvimento do game passe por todas as fases e testes necessários, resultando em um jogo eficiente e bem aceito pelo público (Breyer et al, s.d).

O Design é essencial ao desenvolvimento de jogos. A ele estão relacionadas as fases da criação do projeto, testes, concepção, entre outros (Perry et al, 2007). Um bom Game Design resultará em um bom resultado final para o jogo.

\section{GAME DESIGN: O PROJETO DE JOGOS}

O "game designer" tem um papel de extrema relevância para o processo de criação e desenvolvimento de um jogo. Suas funções na equipe são diversas: pode atuar na escrita de documentos sobre o Design, na determinação dos objetivos e da lógica do jogo, projetação da interface a que o usuário terá acesso, concepção da história do jogo e seus diálogos, além de realizar testes com o software para garantir seu bom funcionamento (Junior et al, 2002). Todas essas responsabilidades expõem o 
fato de que a função desse profissional não se restringe à arte visual do jogo, mas sim à visão do jogo como um todo (Tavares, 2005).

Em suma, é responsável por toda a mecânica do jogo. Desde seu funcionamento até as questões de layout e estética, dando início ao game design em si, ao planejar a forma como o jogo irá funcionar e comportar-se diante de um usuário específico. A escolha do público-alvo é um fator ao qual esse profissional deve atentarse desde o início do processo, já que é a escolha do perfil que permitirá a criação das propriedades do jogo em desenvolvimento, grau de dificuldade, controle, contexto, entre outras características (Sato, 2010).

A participação do game designer finda apenas após o jogo estar completamente terminado e testado. A concepção inicia já tendo diversas informações como base: enredo, universo em que o jogo será ambientado, história do personagem principal ou até mesmo a mecânica do jogo.

Brathwaite (2009, apud Sato, 2010) explica que o "game design é o processo de criar a disputa e as regras de um jogo", além de frisar a importância de buscar promover a motivação para o jogador, por meio de objetivos.

Existem diferentes recomendações para o auxílio do desenvolvimento de um bom game design. Algumas podem ser encontradas no modelo "The 400 Project", de Barwood e Falstein (2006, apud Alves e Padovani, 2006). Dentre elas, podem-se citar a necessidade de identificar limitações do jogo, possibilitar que o jogador explore o mundo apresentado, permitir que os mesmos deixem o jogo, além de ser divertido. Um bom game design garante que o jogador se sentirá integrado à história do jogo, facilitando suas escolhas e decisões (Sato, 2010).

Outras recomendações também foram sugeridas por Federoff (2002, apud Alves e Padovani, 2006), que as subdividem em três diferentes categorias: "Interface, Mecânicas de Jogo e Gameplay". Afirma-se que, para um game design eficaz, é necessário que os controles referentes ao jogo sejam aprendidos de forma fácil e intuitiva; a interface seja simples e de fácil entendimento; a escolha de cores, tipografia e diálogos deve ser condizente com o tema proposto; ser possível corrigir um erro que apareça com auxílio de mensagens fornecidas pelo sistema; ter uma boa história e bons efeitos aplicados (Peres et al, 2012).

O estudo da mecânica a ser desenvolvida para o jogo é outro tópico que precisa ser analisado desde o início da concepção, pois ela será responsável pela interação e funcionamento do jogo (Sato, 2010).

\section{INTERFACE}

A jogabilidade é importante fator a ser estudado durante o processo de criação de um jogo. É ela quem vai determinar a experiência que o usuário terá ao entrar em contato com o game, além de ditar o modo como o jogador irá atingir os propósitos pré-determinados do jogo (Medeiros, 2015). Uma boa jogabilidade necessita de uma interface bem desenvolvida e compreensível ao usuário.

Ao iniciar qualquer software, o primeiro contato pode afetar a opinião primária do usuário, levando-o a criar um pré-conceito tanto para uma opinião boa quanto para uma ruim. Por isso, uma boa interface é essencial ao jogo, uma vez que sua análise primária acaba por influenciar tanto a aceitação do usuário quanto o próprio funcionamento do jogo (Barros, 2015). É a interface que vai ser responsável pela 
comunicação entre o usuário e o software, e é através dela que o sistema irá transmitir toda a informação e objetivos necessários ao jogador (Souza, 1999, apud Barros, 2015).

Cybis (2010) explica que "o trabalho envolvendo o uso de um software será menos produtivo se o software for desnecessariamente difícil de usar. O usuário tem um objetivo relacionado ao seu trabalho, então ficar 'brigando' com a interface não faz sentido". O autor ainda explica que o usuário precisa usar o seu tempo no jogo preocupando-se com a atividade de jogar em si.

A interface precisa garantir uma boa comunicação entre o sistema e o usuário, facilitando as interações com o software (Ellwanger et al, 2013). Se for projetada sem levar em consideração tais cuidados e informações, pode despertar frustração e sentimento de falha nos usuários. O designer deve ter sempre em mente a forma como irá ocorrer a interação entre o jogador e o sistema e levar em conta que a interface precisa divergir entre cada jogo com diferente temática criada, para facilitar a interação da pessoa com o mesmo (Barros, 2015).

Não só de jogos para entretenimento é feito o mercado: hospitais, escolas e instituições públicas fazem uso de jogos para levar informação para quem precisa. Uma boa pesquisa e desenvolvimento de interface para jogos com finalidade educacional ou terapêutica são de suma importância, pois além de atrair e prender a atenção do aluno ou paciente, é pela interface que se dará a comunicação do usuário com o seu responsável, permitindo que o profissional avalie seu desempenho (Ellwanger et al, 2013).

Independentemente da finalidade do jogo, ele deve possuir uma interface visualmente atrativa ao jogador e relacionada com a história e tema que serão apresentados, permitindo maior imersão do usuário (Barros, 2015).

\section{USABILIDADE}

Medeiros (2015) expõe a conceituação de usabilidade pela ISO/IEC 9126, colocando como "um conjunto de atributos de um software relacionado ao esforço necessário para seu uso e para o julgamento individual de tal uso por determinado conjunto de usuários". Relata ainda a importância de algumas características da usabilidade, como a 'inteligibilidade', que permita aos usuários entenderem as características e funcionalidades de um software; a 'apreensibilidade', capacidade do software de permitir o aprendizado do seu uso por quem irá manuseá-lo; e a "atratividade", relevante para chamar a atenção de um possível usuário, entre outros (Medeiros, 2015).

É sabido que jogos são fortes instrumentos de aprendizagem e tratamento, além de estimularem e motivarem o usuário. Porém, para sejam bem sucedidos, os jogos precisam possuir uma usabilidade apropriada tanto ao propósito quanto ao usuário alvo, facilitando seu uso pelo mesmo. Caso contrário, o jogo pode vir a ser de difícil manuseio e entendimento, levando o jogador a largá-lo, e fazendo com que o software desenvolvido perca seu propósito (Gurgel et al, 2006).

Nielsen (1993, apud Freire et al, s.d.) explica que o software que possui uma usabilidade eficiente permite que usuário aprenda a interagir de forma descomplicada, tornando seu uso efetivo e com poucas ocorrências de erro, cumprindo a função junto ao público-alvo para o qual foi designado.

Apesar do entretenimento não ser o objetivo principal em alguns jogos, o desenvolvimento de uma usabilidade adequada não exclui totalmente esse fator. Ao 
iniciar o processo de elaboração do jogo, é necessário pensar no quanto será desafiador ao usuário e contemplar etapas criadas de forma criativa, tornando agradável a experiência e permitindo estímulos que conquistem atenção (Peres et al, 2012).

Deve-se, contudo, atentar que os jogos voltados para o ensino e reabilitação precisam de maior cuidado no desenvolvimento da interface e consequente usabilidade, uma vez que seu uso eficiente pelo usuário, aluno, ou paciente se dará apenas se o jogo proposto atuar da forma desejada pelo profissional responsável, resultando em aprendizado ou na melhora durante o tratamento. Apesar de ser relativamente recente, a preocupação com a usabilidade nos jogos deve ser constante e presente, principalmente no desenvolvimento daqueles com finalidades mais sérias (Gurgel et al, 2006).

A preocupação com pontos de salvamento durante o jogo, obtenção de feedback, facilidade, complexidade e funcionamento de um jogo são algumas das questões a serem estudadas ao se pensar em usabilidade. Esses são alguns dos fatores que o game designer e a equipe que participará da produção devem atentar ao iniciar o desenvolvimento de tal software. Tais fatores devem ser aplicados de forma crítica, visando ampliar a motivação do futuro usuário. Ao atender tais necessidades, o game designer irá garantir que o software esteja apto a proporcionar desafios e diversão ao usuário. Para os jogos voltados para reabilitação ou ensino, o cuidado com esses pormenores deve ser alvo de maior atenção para não torná-los enfadonhos para os usuários, impossibilitando-os de assimilarem o que se almeja ensinar e alcançar (Gurgel, et al, 2006).

Um jogo precisa permitir que o usuário tenha sensação de liberdade enquanto o utiliza, seja para fazer escolhas, resolver desafios, avançar fases ou explorar o universo em que se insere a trama de forma completa. Porém, a atenção com a usabilidade não deve se voltar apenas à jogabilidade, mas também se os controles do jogo serão facilmente assimilados, repercutindo na interação com as áreas prévias ao início do jogo e menus de pausa. É função do game designer atentar a esses fatores, reduzir o tempo que o usuário "perde" ao tentar entender como acontece o jogo e como precisa interagir com ele e otimizar o tempo que o usuário ficará imerso na atividade, levando ao mesmo tanto diversão como aprendizagem e/ou reabilitação, garantindo o entusiasmo do jogador e a consequente continuidade do jogo e do processo. São fatores decisivos tanto de uso quanto de compra de algum jogo as questões de interface, de interação com elementos dos jogos, fluidez das informações, e entendimento das possibilidades que o sistema oferece (Gurgel et al, 2006).

Diversos testes são realizados para garantir a efetividade da usabilidade de um jogo, permitindo que os responsáveis pelo desenvolvimento do mesmo corrijam eventuais erros que possam aparecer e evitar outros. A simples observação de um possível usuário utilizando o software desenvolvido, com posterior feedback do que achou do jogo, são formas de avaliação, assim como avaliações heurísticas e prototipagens (Peres et al, 2012).

\section{6. AVALIAÇÃO HEURÍSTICA}

A avaliação heurística é uma forma de avaliação de interfaces e tem como base uma lista de requisitos previamente estabelecidos. Visa identificar e solucionar possíveis problemas ainda no processo de desenvolvimento da interface, evitando 
erros ao final do desenvolvimento e novos gastos para resolver problemas que poderiam ter sido evitados (Cuperschmid e Hildebrand, 2013).

É realizada por profissionais que entendem do assunto que está sendo discutido e que possuem capacidade para examinar o jogo em busca de problemas e obstáculos que podem atrapalhar o futuro jogador. Diversos itens são avaliados a partir de uma lista pré-estabelecida e, feita de forma eficiente, permite rápida obtenção de resultados. A avaliação heurística é uma ferramenta para a deteç̧ão de erros e possíveis melhorias; não é sua função explicar formas de resolver os problemas encontrados (Cuperschmid e Hildebrand, 2013).

As heurísticas atuam como linhas guias para orientar os avaliadores durante 0 processo de teste, mostrando a eles pontos importantes a serem analisados, permitindo otimizar o tempo de todo o processo (Medeiros, 2015).

Dentre as heurísticas utilizadas, algumas das mais conhecidas são as dez heurísticas propostas por Jakob Nielsen. São elas: 'a visibilidade do estado do sistema', 'mapeamento entre o sistema e o mundo real', 'liberdade e controle ao usuário', 'consistência e padrões', 'prevenção de erros', 'reconhecer em vez de relembrar', 'flexibilidade e eficiência de uso', 'design estético e minimalista', 'suporte para o usuário reconhecer, diagnosticar e recuperar erros', 'ajuda e documentação' (Cybis, 2010).

A aplicação das heurísticas pode ocorrer em qualquer fase do processo de desenvolvimento da interface, desde a sua concepção, até quando ela já está quase pronta para passar para produção de fato (Medeiros, 2015).

\section{PROTOTIPAGEM}

Durante o processo de criação de qualquer produto, discutem-se diversas ideias acerca do mesmo. No desenvolvimento de um jogo eletrônico, não é diferente. Uma forma de se avaliar se tais ideias serão úteis é por meio da construção de protótipos. Tal técnica permite obter uma noção de como o imaginado irá funcionar e se realmente servirá para o propósito ao qual ele foi pensado. Pode ser executada durante diferentes etapas no processo de desenvolvimento e pode possuir ou não detalhes que se assemelhem ao produto final proposto (Medeiros Filho, 2013).

De acordo com Moraes e Santa Rosa (2008), um protótipo é "uma representação limitada de um design que permite aos usuários interagir com ele e explorar a sua conveniência". Podem-se desenvolver e utilizar protótipos que sejam representações em escalas reduzidas do produto final que se deseja, softwares ainda em desenvolvimento ou simples representação em papel do conceito finalizado do produto (Moraes e Santa Rosa, 2008).

A prototipagem do jogo proposto mostra-se como uma forma eficiente de avaliação. Por meio de tal técnica, é possível pré-visualizar como o usuário irá interagir com o produto depois de finalizado e obter opiniões acerca do mesmo. Permite que a equipe de desenvolvimento corrija ou melhore pontos que julgue necessários e esclareça dúvidas que possam existir previamente à concepção do protótipo. 0 protótipo é feito de forma a simular o que virá a ser o produto proposto, já possuindo algumas das suas características finais. Ajuda a perceber se os objetivos tencionados pelo jogo serão bem entendidos e alcançados, a interação do usuário com o produto, permite confirmar se a plataforma escolhida para a execução do mesmo é apropriada e que a equipe responsável pela divulgação conheça o jogo e inicie o desenvolvimento 
da proposta midiática. É importante ressaltar que os testes com os protótipos não devem se restringir apenas à empresa e equipe responsável, mas alcançar os possíveis usuários dos mesmos (Moraes e Santa Rosa, 2008; Sato, 2010; Gurgel et al, 2006).

A prototipagem é importante inclusive durante o processo de construção do conceito do jogo, pois permite perceber como uma ideia primária será desenvolvida e representada no jogo, juntamente com sua finalidade (Sato, 2010).

São dois tipos de protótipos: os de baixa-precisão e os de alta-precisão. Os primeiros são construídos fazendo uso de materiais simples e baratos, como papel e cartolina, sem relação com os materiais que virão a ser utilizados na concepção e execução do produto final; são muito usados por serem rápidos e fáceis de serem construídos e permitirem a pré-visualização da ideia. Já a prototipagem de altaprecisão visa construir um material que se assemelhe àquele que será apresentado no produto final, muito semelhante à ideia proposta finalizada (Moraes e Santa Rosa, 2008). No caso de um jogo, uma prototipagem de alta-precisão seria a representação da interface sugerida, bem como a possibilidade de executar certos comandos e caminhos, testando se as ideias pretendidas estão sendo bem assimiladas e aceitas pelos usuários.

A construção e desenvolvimento de protótipos é, portanto, de suma importância desde o início da concepção do jogo para pré-visualizar se as ideias sugeridas serão eficientes, se poderão ser desenvolvidas e se o futuro usuário terá um bom entendimento da mecânica do jogo, sem se restringir a testar apenas os conceitos empregados no desenvolvimento do software (Sato, 2010). De acordo com a autora, "após se estabelecer o conceito geral, alguns testes são necessários para verificar a viabilidade da representação de uma determinada situação no jogo a fim de conferir credibilidade ao elemento proposto".

\section{CONCLUSÃO}

É indubitável a influência, importância e presença de jogos no cotidiano atual. Seja como um rápido passatempo, uma partida profissional ou mesmo para ser utilizado na reabilitação, é possível observar pessoas de diferentes classes fazendo uso dos jogos em diversos tipos de ambientes. Assim como seu uso, os cuidados durante os processos de desenvolvimento e as técnicas utilizadas para a avaliação dos jogos também aumentaram, e é nesse momento que a participação do designer e dos próprios usuários pode ser a chave para um bom produto final. Utilização correta das técnicas de desenvolvimento, pesquisas para um bom referencial teórico e clareza no objetivo proposto pelo jogo são elementos diferenciais para o sucesso do projeto.

O usuário, inclusive, é fator fundamental para esse desenvolvimento. A forma como o usuário irá interagir com o software que será criado deve ser estudada com bastante cuidado. É nesse âmbito que pesquisas e estudos sobre a interação humanocomputador se encaixam de forma significativa, pois são imprescindíveis para validar as ideias utilizadas no desenvolvimento do jogo, garantindo que o mesmo seja bem entendido e aproveitado pelo usuário.

O uso de pesquisas, métodos e técnicas para o desenvolvimento de games não deve ser feito de maneira apenas superficial, já que servem como linhas guias auxiliares para o designer e permitem a ele entender melhor o comportamento do usuário, suas vontades, manias, maneiras de interagir com um produto, desejos, desafios e tudo o mais que permita desenvolver um jogo que atenda às necessidades 
desse público-alvo, seja por diversão, reabilitação ou educação. O bom jogo é aquele que consegue atingir o objetivo de "prender" o jogador, não deixando que ele desista do desafio proposto.

\section{REFERÊNCIAS}

ALVES, Dayvisson M.; PADOVANI, Stephania. Estabelecendo relações entre critérios de avaliação ergonômica em $\mathrm{HCl}$ e recomendações de game design. Recife: Universidade Federal de Pernambuco, 2006.

BARROS, Maisa de Souza. Estudo de usabilidade em jogos educativos 3d: um estudo de caso. 2015.

BREYER, Felipe B.; MOURA, Dinara; PADOVANI, Stephania; NEVES, André. AVALIAÇÃO DE USABILIDADE NO PROCESSO DE DESENVOLVIMENTO DE JOGOS. [s.d.]

CUPERSCHMID, Ana Regina Mizrahy; HILDEBRAND, Hermes Renato. Avaliação Heurística de Jogabilidade. SBC-Anais do SBGames, São Paulo, SP, Brasil, p. 371-378, 2013.

CYBIS, Walter; HOLTZ, A.; FAUST, Richard. Ergonomia e usabilidade. São Paulo: Novatec, 2010.

ELLWANGER, Cristiane. KID+: Sistema para Gerenciamento de Jogos Digitais Educacionais com Desenvolvimento Guiado por Preceitos de Usabilidade. 2013. FREIRE, Fernanda Maria Pereira; DA SILVA, André Constantino; DOS REIS, Carolina Fernandes. MUDANÇAS CONCEITUAL E DE MODALIDADE: IMPACTOS NA USABILIDADE DE JOGOS DIGITAIS. RENOTE, v. 13, n. 1. [s.d] GURGEL, Ivannoska et al. A importância de avaliar a usabilidade dos jogos: A experiência do virtual team. Anais do SBGames, Recife, 2006.

JUNIOR, Ademar de Souza Reis; NASSU, BOGDAN T.; JONACK, MARCO ANTONIO. Um estudo sobre os processos de desenvolvimento de Jogos Eletrônicos(Games). IN: HTTP://WWW. ADEMAR. ORG/TEXTOS/PROC_DESENV_G AMES/PROC_DESENV_GAMES. PDF, 2002.

LUCCHESE, Fabiano; RIBEIRO, Bruno. Conceituação de jogos digitais. Sao Paulo, 2009. MEDEIROS FILHO, Marisardo et al. A importância da prototipação no design de games. SBC - Proceedings of SBGames. 2013.

MEDEIROS, Jerry Fernandes. Avaliação de Usabilidade e Jogabilidade em Jogos para Dispositivos Móveis. 2015.

PERES, Angela Lima et al. Estudo dos elementos de interatividade recomendados em jogos e a satisfação na experiência dos jogadores de The Elder Scrolls V: Skyrim ${ }^{\circledR} \mathrm{e}$ Left 4 Dead $2^{\circledR} .2012$.

PERRY, Gabriela T. et al. Necessidades específicas do design de jogos educacionais. Sociedade Brasileira de Computação-SBGames, Porto Alegre, 2007.

TAVARES, Roger. Fundamentos de game design para educadores. I Seminário Jogos Eletrônicos, Educação e Comunicação-Construindo novas trilhas, 2005. 